Instituto de Estudos Sócio-Ambientais

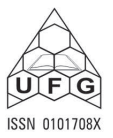

BOLETIM GOIANO DE GEOGRAFIA

v. 26, n. 1, jan./jun. 2006

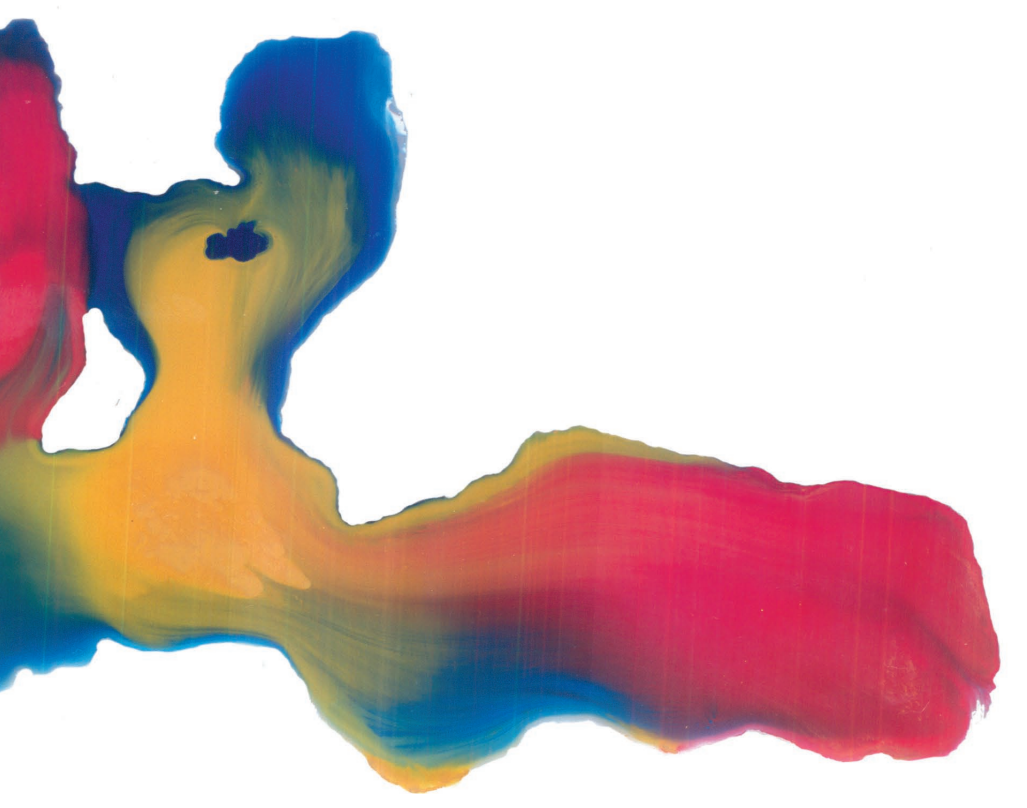

$\infty$
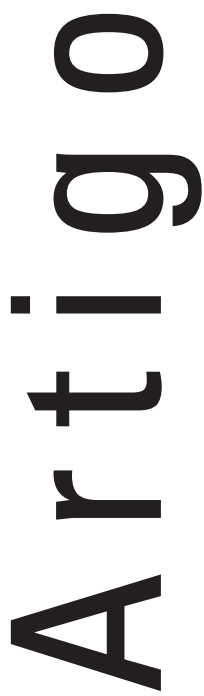


\title{
DO ESTUDO DO MEIO AO TURISMO GEOEDUCATIVO: RENOVANDO AS PRÁTICAS PEDAGÓGICAS EM GEOGRAFIA
}

\author{
ENVIRONMENT STUDY AS GEOEDUCATIVO TOURISM: \\ RENEWINA THE PRATICAL PEDAGOGICAL IN GEOFRAPHY
}

\author{
Christian Dennys Monteiro de Oliveira - UFC \\ c49@uol.com.br
}

\section{Resumo}

0 presente artigo desenvolve uma reflexão a respeito do Estudo do Meio, enquanto metodologia organizada das aulas de campo em Geografia. Trabalha com a demonstração conceitual de suas duas naturezas. Uma diretamente ligada à busca de conhecimento empírico e aberta à realidade exterior à sala de aula. Porém, submetida aos limites de uma ação científica limitada à exclusiva confirmação do que está sendo estudado no interior da escola. A segunda, aberta a utopia de recriar as metodologias escolares a partir desse tipo de estudo. Na parte final desse artigo é revisto o sentido de estudo do meio na atualização das práticas de um turismo educativo, mais acessível à escola contemporânea e como melhores condições de reconciliar as duas naturezas em questão.

Palavras-chave: estudo do meio, natureza científica, escola, turismo geoeducativo.

\begin{abstract}
The present article develops a reflection regarding the Environment Study, while organized methodology of the lessons of field in Geography. It works with the conceptual demonstration of its two natures. The first one directly searches of empirical knowledge. Open exterior reality to the classroom. However, submitted to the limits of a limited scientific action to the exclusive confirmation of what he is being studied in the interior of the school. The second opened the utopia of re-create the pertaining to school methodologies from this type of study. In the final part of this article, it is revised at the direction of in the update practical them of an educative tourism, accessible to the school contemporary and as better conditions to reconcile the two natures in question.
\end{abstract}

Key-words: environment study, scientific nature, school, geoeducativo tourism. 


\section{Introdução}

A questão mais central do Ensino de Geografia, na perspectiva desse ensaio, é discutir como regra uma prática pedagógica permanentemente reduzida à exceção. No fundo, dá-se vazão a um debate sobre a essência de uma educação geográfica. Aquela educação que se esconde, mas pode vez em quando, se revelar no interior desse Ensino.

O Estudo do Meio estabelece uma investigação sistemática dos lugares, conduzida pelo coletivo dos alunos e coordenada por um professorpesquisador. Trata-se de um processo de revelação pedagógica das infinitas potencialidades da geografia escolar em diálogo operacional como a geografia cotidiana. Diálogo esse que vem sendo assumindo dentro de uma postura político-pedagógica relacional, novas aberturas e fechamentos. Abertura à incorporação de saberes espaciais não científicos, densos de significação cultural e ambiental, além de estratégicos, na manutenção das coletividades. Fechamento à força retórica de uma geografia que quer generalizar realidades em escala-mundo, discutindo os espaços locais apenas como subprodutos de uma "unidade" global. Nessa geografia mundana em formação (Oliveira, 2004b), a idéia de que o globo terrestre é um lugar só e único não tem vez. Vale apenas como mitologia científica.

A oportunidade de discutir o Estudo do Meio, nesse breve exercício, justifica-se pela apresentação de novas tendências práticas e regulamentares que motivam sua atualização. O questionamento de fundo encontra-se na seguinte possibilidade: pode um trabalho de campo (tradicional recurso didático da Geografia) ser dinamizado na perspectiva educacional de uma prática turística? Em outras palavras, o estudante da disciplina de geografia (no ensino básico) faz turismo pedagógico quando estuda uma localidade?

A resposta dessa provocação será composta em duas partes. A primeira, recuperando as características e que reconhecem o poder educativo do Estudo do Meio, mas não supera os dilemas conjunturais e educativos capazes de tornar essa prática uma condição sine qua non da Geografia Escolar. Na segunda parte, será percorrida uma estrada aparentemente sinuosa, capaz de indicar uma atualização do Estudo do Meio, na perspectiva do Turismo Educativo. Serão apresentadas as bases da visitação como prática cultural de um turismo geoeducativo, alicerçado pela inversão das perspectivas que fecham turismo como sinônimo de "ócio" e de hospedagem à "estrangeiros".

A identidade entre a força pedagógica da geografia no campo e a capacidade educativa do turismo, reúne condições para outra leitura a respeito dos Estudos do Meio. 


\section{Pensando o estudo do meio}

Toda Geografia poderia ser Estudo do Meio. Afirma Debesse-Arviset (1974) em um dos subtítulos de sua instigante reflexão sobre a ruptura que persiste no Ensino básico da Geografia, entre o texto e o contexto ${ }^{1}$.

Uma geografia do meio impõe, não somente um conhecimento, mas um certo respeito do meio ambiente. Permite que a criança ou o adolescente penetre no domínio das leis da vida... Ficam assim os alunos preparados para compreender as interdependências que ligam a vida ao seu meio, o perigo das reações em cadeia que um ato impensado é capaz de promover. (Debesse-Arviset, 1974, p. 17)

Paradoxalmente, grande parte dos argumentos responsáveis pela renovação da Educação em geografia, nas ultimas décadas, permanece ecoando um "meio" fortemente avesso ao reconhecimento desta condição elementar. Afinal, pode-se contar nos dedos a quantidade de escolas onde o planejamento de geografia começa por um trabalho sistemático de Estudo do Meio (ou EM). Ou, na melhor das hipóteses, aproveita toda uma gama de estudos - ainda que fragmentados - realizados no ano anterior para subsidiar o plano / projeto de ensino para aquele ano letivo. Mais raros ainda são aqueles exemplos de escola em que o EM funciona como referência permanente dos processos pedagógicos que dinamizam as disciplinas. Simplesmente não há continuidades (horizontais e verticais) ao longo de diferentes anos.

Não se advoga aqui que a realidade mais representativa do ensino de geografia seja fixada exclusivamente no EM. A prática pedagógica não pode e não deve trabalhar em "regime de exceção". Também não se pode confrontar a idealização do autor como um devaneio, politicamente cabível em condições experimentais. Esse e outros pesquisadores do processo escolar da geografia, não se pautam pelo impacto resultante da denúncia de uma situação inadequada. Mas sim, pela capacidade de sua argumentação potencializar as práticas de quem ensina e aprende geografia, no pertinente enfoque da compreensão e não só do conhecimento científico acumulado. Conhecer mais geografia pode jamais significar compreender melhor geografia. A visita do Pequeno Príncipe ao planeta do geógrafo demonstra cristalinamente esse processo.

O tema proposto para discussão será aqui tratado de maneira qualitativa, no sentido de apontar que a prática pedagógica da Geografia, e toda ela, já tem sido, há muito um permanente Estudo do Meio. Algumas vezes, sim pautado pelas lógicas exasperadas: saída (e retornos), interação, pro- 
posição dos diversos agentes, demonstração de avanços e autocríticas. E, indiscutivelmente não faltam exemplos admiráveis (no sentido mesmo de mirar interiormente). Temos recolhido dos Encontros Nacionais de Prática de Ensino em Geografia, no âmbito mais específico, e dos eventos bianuais da Associação dos Geógrafos Brasileiros uma preocupação sempre expressiva na demonstração da versatilidade do EM.

Porém, em outras tantas vezes o conceito de meio, apresentado entre aspas e referendado por um conjunto de mediações e maquiagens, realiza-se no engessamento da realidade geografia às necessidades dos "pré-conceitos" trabalhados à exaustão. Percorrer quilômetros de descampados nas áreas rurais e condenar isso à culpa do poder do latifúndio, ou observas a mobilidade comercial do centro de uma cidade grande e indicá-lo como "caos urbano" é quase um movimento de conceituação natural. Para boa parte dos professores de geografia o Meio deve apenas confirmar o que não teria ficado suficientemente claro para o estudante, dentro da sala de aula. A finalidade dessa confirmação é trocar o meio pelo fim. E neste sentido, força-se a metodologia do Estudo do Meio como uma forma de Revisão Prática (ou pragmática) do conhecimento geográfico. Isso é de uma pobreza quase infinita, mas é a regra geral em vigor.

Só para ilustrar esse primeiro movimento crítico a respeito do que seja desfazer o Estudo do Meio na prática de sua realização, vejamos um exemplo hipotético.

Uma dada Escola pública paulistana tem um programa temático para trabalhar Geografia de $7^{\mathrm{a}}$ e $8^{\mathrm{a}}$, dentro de um ciclo de estudos de problemas do mundo moderno. Em dado momento, com duas turmas das séries mencionadas é montada uma programação que visa compreender o sistema de transportes urbanos e seus desafios técnicos e territoriais. Para tanto, agendou-se uma visita às instalações administrativas do Metrô de São Paulo, com a possibilidade de reconhecimento, na mesma data de uma das áreas de estacionamento e manutenção dos trens.

Para surpresa geral, a escola e os organizadores receberam a notícia de uma de greve dos ônibus da capital, marcada para o dia da visita. Não foi suspensa a visita e no dia marcado, a greve também não atrapalhou a programação ou modificou os horários estabelecidos. Apesar de todos transtornos urbanos relacionados ao episódio - vivido, por alunos, agentes escolares, pais, funcionários da Companhia do Metro, inclusive - nada foi registrado nos relatórios, elaborados como produtos finais do estudo. A orientação previamente estabelecida direcionava uma ênfase exclusiva ao sistema (en- 
quanto abstração técnica) não o contexto do sistema (em seu cotidiano jogo de tensões e improvisos).

Eis a dinâmica perversa que tende a empobrecer a prática pedagógica da Geografia, justamente quando uma maquiagem de Estudo do Meio vem se impor como atividade prática e eficiente e, ao mesmo tempo, mecânica. O meio não é um veículo de transmissão de idéias. É, acima disso, um caminho para a construção dessas. Mas que idéias construir sobre o sistema de transporte urbano se um conjunto de trabalhos a respeito do metrô paulistano simplesmente ignora uma realidade de greve de ônibus. Nesse viés, o meio estudado nunca é o Meio Ambiente. De que meio as aulas de campo de Geografia querem tratar afinal?

Considerando que a experiência acima pode transparecer como regra geral de uma prática de redução dos riscos, tem-se uma pista para o desuso do EM na geografia escolar atual. É impossível realizá-lo sem permanente incorporação e enfretamento dos riscos. Nestes termos, os limites de uma cultura da segurança bloqueiam quaisquer ampliação tal prática. E de forma mais consistente do que os alegados motivos financeiros ou burocráticos presentes em quase todas as escolas. Mesmo o baixo prestígio que se alega existir na disciplina geográfica, diante do Ensino Básico, nunca foi motivo suficiente para a rarefação de atividades externas.

O problema central fica evidente em dois pólos, que se quer aqui discutir, no plano das definições e da critica conceitual: $1^{\circ}$. Quando a escola e a disciplina de Geografia assumem a realização do Estudo do Meio, um reducionismo cientifico é imposto a esse mesmo e tamanho que só lê resta pedagogicamente um caminho: de reafirmar os muros da instituição escolar - e, por conseguinte, do método cientifico, do séc XVIII / XIX - como o parâmetro único de seus resultados; $2^{\circ}$. Na grande maioria das vezes que um caminho mais significativo de Estudo do Meio é previsto (sem carregar a nomenclatura, mas a natureza) sua realização faz-se de pequenos experimentos e intercâmbios aferíveis no próprio meio, do qual a escola e a matéria de Geografia são apenas um entre tantos componentes.

A primeira constatação evidencia um ranço negativo - e dominante - capaz de direcionar os pacotes de atividades programadas cada vez mais “administradas” no marketing escolar. Qualquer instituição de porte empresarial e campeã na aprovação de estudantes dentro dos mais concorridos vestibulares possui uma rede de fornecedores de serviços de viagem. Nunca foi tão elevada a quantidade de agências, além de transportadoras e empresas de lazer, prestando serviços para escolas de "alto padrão". Sinal de um 
tempo em que o conhecimento do meio exterior deveria ser tão terceirizado como a produção das técnicas didáticas e científicas. E esse padrão de qualidade não se restringe às escolas particulares das principais capitais. Avança como modelo de qualidade educacional para um significativo grupo de instituições públicas.

Já a segunda assertiva - mais positiva, mais criativa e menos visível - lembra que o Meio em estudo não é passível e pode, de maneira quase permanente chamar a escola (e a disciplina de geografia) a uma interação; sutil sim, mais formativa também. Digamos que a partir de um trabalho multiplicador, os relatórios discentes sobre o metrô explorassem, os dilemas do transporte da comunidade escolar em seu cotidiano urbano. Era possível, ao mesmo tempo trabalhar as interfaces desse assunto com outros temas e ampliar a visibilidade da relação entre conhecimento e compreensão da realidade. A natureza de um problema se revela em soluções viáveis a medida que o exercício educativo ultrapassa as superficialidades e se dirige a aprendizagem compreensiva. O educador e filósofo Antonio Muniz de Rezende, em seu trabalho Concepção Fenomenológica da Educação (1990) nos lembra sobre isso que o problema pertinente da educação se constrói (e avança) no desafio da aprendizagem. E essa aprendizagem possui sempre uma natureza cultural.

Há uma "primeira natureza" no processo que se convencionou a chamar de Estudo do Meio pelo simples fato de direcionar os alunos para uma relação de aprendizagem com o "mundo exterior”. Há uma "segunda natureza”, que merece ser explorada, mesmo diante das padronizações facilitadoras existentes na primeira. Contudo pode ignorar a primeira, emergência de uma cultura cotidiana - que nunca deixa de ser natureza - põe os padrões de estudo e escolarização em permanente ameaça ao que está dado; ao que apenas é tópico e não altera o processo porque rejeita a $u$-topia de forma precipitada.

E não deixemos de observar que a recusa da utopia é exatamente o que caracteriza aqueles que "realisticamente" pretendem permanecer dentro da tópica no sentido atual. O utópico é o desejo do que falta. Melhor, é o desejo dos que faltam. Por todos esse motivos é que a fenomenologia da educação não pode deixar de suscitar o problema dos objetivos educacionais. (RESENDE, 1990, p. 81)

Mas de que maneira a geografia pode pautar-se por um Estudo do meio de natureza cultural tão arriscada? Transformando-o em estudo do meio re-idealizado? 


\section{A natureza idealizada do estudo do meio}

Por definição preliminar, um estudo do meio se configura como um conjunto de atividades programadas - pela disciplina geográfica ou em planejamento interdisciplinar - no sentido de promover a compreensão mais direta da realidade sócio-ambiental do aluno, por intermédio do trabalho de campo. Obviamente, como lembra Debesse-Arviset (1974), este conceito de meio está subordinado à delimitação/diferenciação de meio geográfico. Mesmo porque, além das múltiplas significações que a palavra meio pode conter nas línguas latinas, é preciso distanciar-se da pressa em conectar meio $\rightarrow$ meio ambiente $\rightarrow$ meio natural $\rightarrow$ o não humano.

Caminho simples para definição e sugestão de trabalho metodológico pode levar a prática pedagógica do Estudo do Meio a se limitar em "técnica didática”. O fato do EM vir a conter muitas técnicas (de pesquisa empírica, documental, participante) e diferentes efeitos para interação da ambiência escolar (a escola e seu entorno), não restringe a força teórica de sua prática. Ao contrário, esse processo dá fundamento lógico e convincente ao porquê da teoria. A escola e a geografia não são indispensáveis, apenas por nos constituir cidadãos plenos; mas acima de tudo porque este é um dos poucos micro-espaços que podem ajudar o Meio, interativamente, a constituir-se como Paisagem, como Lugar, como Território. O meio ambiente contemporâneo, também via escola, constitui-se em rede mundial de Cidadania (para seguir a linguagem dos atuais Parâmetros Curriculares Nacionais).

A natureza do Estudo do Meio, idealizada sim, mas realizável enquanto prospectiva da utopia, é transformadora, criativa e coerente com os mais valiosos propósitos científicos, das diversas correntes de pensamento.

Entretanto, a natureza desse estudo também acumula etapas, dinamiza-se, incorpora ações e reações (quando não retaliações), atinge resultados e converte-se em produto; que se disponibiliza, tal qual uma mercadoria, a um processo complexo de para exportação.

Trabalhos muito interessantes realizados na perspectiva da ação transformadora, em pequenas cidades interioranas; nos conflitos de velhos e novos bairros que se remodelam em grandes cidades; nos impasses locais tão desafiadores aos processos que ao mesmo tempo se opõem e se complementam. São eles: poluição \& modernização, desenvolvimento \& desemprego, migrantes \& autóctones, etc. Todos com elevada capacidade de impulsionar a renovação da geografia dos lugares e nações. Mas limitados a gerar na aula de geografia (dentro ou fora da sala) um raciocínio simplista, generalizador 
de fórmulas e confirmador de verdades muito semelhantes ao tão criticado determinismo geográfico.

Claro que os rios das grandes cidades são poluídos! Claro que o clima das serras são sempre mais frios! Claro que o homem moderno está destruindo as matas e o solo! Com tanta clareza, para que arrisca investimentos na realização de trabalhos de campo como EM? A resposta advém de um movimento científico sempre insatisfeito com os resultados e sempre capazes de acrescentar problemas. Seguindo os postulados epistemológicos de Gaston Bachelard e Maurice Merleau-Ponty, há que se formular na escola não as respostas aos problemas do mundo; mas as perguntas mais apropriadas para o confronto das crenças que o mundo teima em utilizar com máxima ingenuidade e ainda chama de "soluções práticas". Nesse momento de inteligência crítica, nenhuma clareza daquelas se mantém em pé.

Um estudo que exemplifica bem esse processo de inconformismo com o dado construção do que pode ser possível, foi produzido pela da equipe de trabalho do professor Cláudio Mauro e publicado pela Associação dos Geógrafos Brasileiros na década passada. O trabalho de campo realizado por sua equipe foi apresentado em um Encontro de Professores, na cidade de Campinas (SP). Era apenas um entre tantos exemplos de demonstração das potencialidades do $\mathrm{EM}^{2}$ Vale destacar a perspectiva de superação do que se convencionou a chamar de programa de conscientização ambiental. Os alunos como sujeitos sociais concretos, são estimulados a perceber e interagir com os problemas ambientais. Entretanto, pouco se trabalha na dimensão do comprometimento, afetivo e responsável desses mesmos alunos com o lugar que os envolve. O risco de tornar, portanto, a denominada Educação Ambiental, um conjunto de propósitos ideológicos bem intencionados sem amarração efetiva com a transformação dos comportamentos é enorme.

A tentativa de enquadramento disciplinar que já se manifestou várias vezes em nome de uma Educação Ambiental mais eficiente pode vir a contaminar os exercícios promissores de estudo do meio. Reigota (1998) lembra que a Educação Ambiental correu o risco de se tornar, por decreto, uma disciplina obrigatória no currículo nacional. Contudo a resistência dos professores evitou que a mesma se tornasse mais uma banalidade pedagógica, perdendo todo seu potencial crítico e questionador a respeito das nossas relações cotidianas com a natureza (1998, p. 47). O alerta é plenamente válido na perspectiva de controlar, passo a passo a metodologia do Estudo do Meio.

Entretanto, o máximo de cuidado deve existir no planejamento daquele estudo, nas escolas da mesma região apontada pelos autores. Muitas vezes 
se ignora que um texto de Geografia do lugar (ou do cotidiano) pode ser tão densamente abstrato e distante quanto o que trata do mercado mundial e da geografia da Rússia para alunos de Catalão, Anápolis, ou diversas cidades interioranas de Goiás ou do Brasil. É diante dos critérios dessa aproximação sensível, objetiva e temática que se pode construir diferentes "métodos" de Estudos do Meio sobre um mesmo lugar ou, em outro extremo, maquiagens de estudo do meio como àquele relatado no item anterior.

Tais maquiagens também colaboram para afirmar que a Geografia forma a espacialidade critica e criativa do aluno. Mas nos avisa que o trabalho dessa pedagogia hegemônica, com finalidades conservadoras, pode formas a espacialidade ideal de um aluno ideal. Mantendo o afastamento entre o texto e o contexto, percebido pelos sujeitos, mas raramente descrito com tamanha representatividade, como no relato do aluno de supletivo da $6^{\text {a }}$ Serie, transcrito por Marcia Resende.

Em Geografia, na minha mente, vem justamente o que eu acabei de dizer: um desenvolvimento de curiosidade, de leitura, de conhecimento, de comunicação. Mais nunca saber do que foi escrito.Então na Geografia o que me traz seria o seguinte: uma coisa que eu acabei de falar, eu não conheço, apenas entrou em minha cabeça: é leitura. Vamos dizer que assim fosse, por exemplo: tamanho do Brasil é [...] Então é isso, não me convencem os livros. (RESENDE, 1986)

Que mecanismos teriam de ser programados na pratica pedagógica dessa Geografia interativa com a capacidade de superar essa desconfiança? Ou estaria justamente nesse não conhecimento do aluno de que a chave-referencial para avaliar a eficiência (técnica e política) dessa pratica pedagógica?

\section{Uma segunda natureza do estudo do meio}

Utiliza-se neste título apenas um trocadilho para se reconhecer que as múltiplas experiências de Estudo do Meio podem ocorrer, tão somente na criação de um projeto especifico para a realidade do contexto escolar. Em outras palavras, preciso demarcar, alguma maneira o quanto a escola e a sala de aula de Geografia estão sendo estudadas como parte do Meio que se propõe investigar. E aí se faz uma opção, mais radical (e por isso mesmo recusando ou marginalizando as nomenclaturas).

Ou se trabalha com a natureza fixa do meio exterior; para o qual convocam-se formas artificiais de traduzi-lo e encerrá-lo como uma outra 
possibilidade de relação sujeito-objeto - conforme pudemos vivenciar em 2 (dois) renomados colégios da capital paulista. Ali, como em outras escolas de padrão educativo elevado, programa-se Estudo do Meio nas férias de julho, e em localidades sem qualquer conexão imediata com a realidade dos educandos! O que nos permitia fazer bem uma geografia de positivismos, funcionalismos e dicotomias.

Ou, na contra-mão, se admite a interdependência do Meio a ser estudado com os sujeitos educando dessa mesma escola. E se elabora a construção paulatina de um compromisso constante e crescente da própria escola com esse Meio. Que nunca se restringe necessariamente ao entorno próximo; mas que verdadeiramente participa dos rumos educacionais ali traçados. Faz-se aqui uma critica construtiva e criativa; em termos geográficos um exercício para a metodologia dialética.

Embora aparente uma natureza ainda mais ideal, é esta segunda natureza que, de forma cotidiana, se impõe nas lições existenciais da geografia escolar. Por analogia podemos dizer que a natureza da Terra está presente na Terra inteira. Mas tão somente em pontos e áreas especificas da superfície do planeta ela é pensada, resolvida e repensada: os territórios humanizados. E são nesses que todas as características da natureza da Terra se tornam imprescindíveis.

Fez-se aqui esse desvio analógico somente para se chegar a força dessa noção do que é imprescindível na prática pedagógica da Geografia. Não é todo e qualquer estudo do Meio nem a técnica de redução mecânica de suas etapas que garante ao Ensino de Geografia uma espécie de sustentabilidade educacional. Somente aquele estudo que responsabiliza (e leva o aluno a se responsabilizar) por esse meio é que converte numa pratica pedagógica além da idealização.

Pois essa é a diferença, aqui de uma abordagem positiva para um encaminhamento dialético. Na primeira somos tachados de idealizar demais e tirar os pés do chão. Daí a convocação conservadora. Na segunda, idealizamos de menos e geramos mais sentido e mais contribuição formativa do que podemos imaginar. Uma leitura de que as realidades (contextos) são sempre muitos mais ricos. Daí a angustia do aluno da professora Resende, ser em parte positiva "culpa" dela. Culpa de todos nós.

Nos jogos da atualidade, no confronto das informações da mídia mercadológica, nos conflitos do mundo do trabalho, da família, do lazer...em todas estas territorialidades visualizam-se pequenos trabalhos e exercícios orientados e criativos. Muitas vezes, se empobrecidos na lógica dos encer- 
ramentos (da aula, da unidade, do bimestre). Mas, via de regra, constituídos em sua latência. Até que ponto o estudo do meio, nesta segunda natureza mais cotidiana, não responderia pelo processo de globalização das culturas? Obviamente de maneira discreta e efetiva?

\section{A efetivação de um compromisso com o meio: por um turismo geoeducativo}

A concepção de Turismo que orienta o enfoque desse texto encontrase na idéia de que seu processo, acima de tudo, conserva uma prática sóciocultural em territórios dinâmicos. Somente depois desse reconhecimento pode-se falar de Turismo como produção moderna, como indústria do ócio e lazer, como planejamento de atrativos (eventos e bens) internacionais. Uma noção de Turismo apenas tele-guiada pelos indicadores quantitativos de fluxos de turistas e investimentos, não ultrapassa o status de um "turismo retórico”. Fala em desenvolvimento sustentável sem jamais poder provar que isso socialmente se efetivou.

Para ultrapassar essa a retórica dominante, propõe-se lidar com uma concepção relacional do Turismo, centrada na noção de visitação. Visitação é uma atividade de intercâmbio, plenamente conhecida na sociabilidade de qualquer grupo social. Especialmente dos grupos que sustentam uma cultura das classes subalternas. Justamente aquelas que praticam o intercambio sem o aporte de investimento do Turismo padrão enquanto aguardam um processo turístico mais emancipador (PRUDENTE, 2005).

A visitação é capaz de garantir todo um conjunto de condutas verdadeiramente sustentáveis, na medida em que reúne e compromete, no processo de visita (que é um turismo genérico), tanto o visitante quanto o visitado. E acrescenta: o lugar visitado nunca é mais importante que os sujeitos envolvidos na visitação. Isso á absolutamente decisivo para apontar onde o processo convencional de turismo - seja em sua forma massiva ou elitista - não se viabiliza mais como prática sócio-cultural e fica apenas circunscrita aos “donos do poder”, seja ele institucional ou empresarial.

Um turismo como visitação é, antes um turismo educativo. De que forma pode estabelecer articulação com a discussão conceitual do Estudo do Meio?

É oportuno relembrar a associação que habitualmente se faz entre Turismo e Lazer e verificar. No passo seguinte, é fundamental verificar como Turismo e Lazer - este aqui compreendido como ato de criação - são manti- 
dos como um "artigo de luxo", dentro de uma sociedade moderna. Balizados por uma construção de prazer ou de desejo, ambas as práticas carregam o incomodo componente da autodeterminação dos sujeitos. Quem visita, quem é visitado, quem brinca ou se diverte, rompe com a determinação externa (e meramente produtiva) de suas ocupações. Aqueles que vivem aprisionados pelo mundo sem lazer não usufruem o direito a esse rompimento e nem ao desejo de praticá-lo. Será?

As origens peregrinas e religiosas do turismo, acrescidas dos processos que relacionam lazer à "missão" dos inúmeros trabalhos do chamado terceiro setor derrubam facilmente essa visão. O turismo religioso, como objeto recorrente de investigação desse autor, tende a ser uma demonstração latente de que a rivalidade lazer X trabalho é uma grotesca demarcação de campos praticamente indistintos. No turismo religioso o lazer é um tempo de trabalho mais árduo e significativo.

Ignorar essa "inversão" é trilhar interpretações que barram a leitura dinâmica da realidade; um simples mecanismo de conforto mental, incapaz de acrescentar qualquer coisa nova no raciocínio exposto. A associação primária entre uma idéia de "turismo" e "uma idéia de lazer”, sugere raciocínios tão equivocados quanto ideológicos. E esse bloqueio é muito bem trabalhado por diferentes pesquisadores dessas áreas, como Marcelino (1990), Camargo (2001) e Molina \& Rodriguez (2001). Felizmente um campo de interpretação não primária é aberto também a partir dos estudiosos do Ensino de Geografia, afinados com as mutações do Estudo do Meio.

A professora Nídia N. Pontuschka destaca-se pela amplitude que estabeleceu em um dos seus trabalhos, ao caracterizar essa mobilidade que atinge a natureza dos Estudos do Meio. Percebendo o avanço que a perspectiva interdisciplinar - e neste sentido, Turismo e Lazer também são disciplinar, contudo não-escolares - a autora firma:

No estudo do meio, o aluno expressa o desejo de compreender o espaço do qual faz parte ou os espaços mais distantes, que aguçam o seu desejo de conhecer. É partindo de referências que estão sendo construídas no processo de apreensão daquela realidade, fazendo comparações, que o jovem vai consegui essa compreensão... O contato direto com um local, seja da realidade do aluno, seja de outras realidades, e a reflexão sobre ele permitem que se formem referenciais para entender que o meio não é estático, é dinâmico. (PontuschKA, 2004, p. 261)

Esse modo de pensar o Estudo do Meio, em sua dinâmica maior, está combinado à visão que torna a sala de aula um lócus exclusivo da sistema- 
tização do conhecimento no exterior. Uma espécie de agência de viagem na prática sócio-cultural do Turismo. A sala é o espaço de aprofundamento de muitas questões sugeridas e documentadas no caderno de pesquisa de campo (PontuschKa, 2004). Até aí é lógico estabelecer o entendimento. Mas por que a idéia de "desejo", de "comparação", de "abertura para outras realidades", dificulta tanto a identificação do Estudo do Meio com as práticas de Turismo?

O grande problema a ser ultrapassado está no fato dos pesquisadores aceitarem, sem contestação nem reflexão, a noção superficial de que um lugar é turístico apenas por seus atrativos. Eis um primeiro absurdo. E continuar esse raciocínio na crença entorpecente de que o Turismo, isoladamente, pode desenvolver um lugar com investimentos pontuais e concentrados; sem a significativa participação das diversas comunidades envolvidas nos fluxos turísticos. E aí está o segundo absurdo. Em outras palavras, a retórica do Turismo Insustentável, chega aos estudiosos (inclusive da geografia) que crêem ver-se diante da única dimensão possível dessa atividade.

A experiência de campo da Geografia forja múltiplas possibilidades de acesso à dimensão relacional do Turismo. E é sobre essa dimensão que pode ser reconstituído o EM, em sua dupla natureza, como prática de um Turismo Geoeducativo. A metodologia que orienta o Ensino de Geografia, como realização permanente de pesquisa da relação escola / entorno, pode constituir uma percepção do fazer turístico como procedimento didático-pedagógico. Para tanto há que se proceder em algumas re-elaborações conceituais referendadas em pedagogia capazes de enxergar a educação mais fora do que dentro da sala de aula. Algo como a pedagogia da "ação cultural" de Paulo Freire ou da "animação" conforme Nelson Marcelino. Uma pedagogia aberta à reconciliação da escola como o mundo; não por reação, mas por proposição, por devir.

O Turismo Geoeducativo permite aos estudantes uma prática de diálogo com os lugares, fazendo-os interagir com atrativos e repulsivos (aqueles elementos que no Turismo retórico não devem ou não podem ser observados). Não busca os lugares em si, como se estes formassem paisagens neutras ou desocupadas. Busca a possibilidade de interação sócio-ambiental constante; mesmo em sua forma invisível ou indireta. Nesse processo concorda com o professor Yázigi (2001) quando reconhece que a identidade antropomórfica dos lugares lhes atribui uma verdadeira alma. 
Não é um turismo que se pauta pelos gastos fornecidos por cada hóspede visitante. Simplesmente porque, filosoficamente falando, no meio ambiente todo ser humano, todo cidadão é um "hóspede". De fato reconhece no nomadismo e na viagem, não no sedentarismo contemporâneo, que está enraizada a cultura do Turismo. E isso é essencial: repensar o processo moderno do Turismo como algo também enraizado na cultura social humana. A Geografia pode nascido no século XIX; mas o saber geográfico tem a idade da relação existencial da Comunidade Humanas com seu espaço vital. Da mesma forma a escola da Revolução industrial é tão somente a recriação contemporânea da sociabilidade do saber coletivo; tão antiga quanto as sociedades humanas. Por que seria plausível pensar a atividade turística, com tanto apelo imagético e discursivo como algo absolutamente novo? Pela mitologia do novo que escamoteia os acessos populares em nome das técnicas mirabolantes. Ou para descomprometer os agentes públicos de que o investimento prioritário no Turismo é de cunho Educativo e Estrutural. Não é uma opção vocacional de alguns lugares e em algumas circunstancias. É um processo generalizável, posto que firmado na necessidade básica de construir novos comprometimentos dos sujeitos com os lugares. Lugares seus que também são lugares dos outros; de muitos outros.

\section{Por finalizar... mas só reiniciando}

A perspectiva de investigação sistemática do processo de crescimento do Estudo do Meio como Turismo Geoeducativo, provocou a sistematização de um projeto de pesquisa, em implantado no Departamento de Geografia da Universidade Federal do Ceará. Trata-se de uma avaliação, por amostragem de municípios do Estado do Ceará, das atividades externas na Geografia do Ensino Básico ${ }^{3}$. Ocorre que os municípios escolhidos correspondem a duas localidades de uma das sete macro-regiões turísticas do Estado, definidas pelo programa de Regionalização do Turismo brasileiro. Parte-se da hipótese a quase inexistência de Estudos do Meio nas escolas corresponda ao desperdício de significativos roteiros locais inexplorado até pelo lazer das comunidades.

Espera-se que esse e outros estudos possam corroborar para a desmistificação do turismo como instrumento pedagógico de valioso aproveitamento no Ensino de Geografia. 
Na construção de uma síntese em provisória finalização é possível, didaticamente, estabelecer alguns tópicos como exercício demarcatório. O esclarecimento dos mesmos pode ficar para um debate posterior, a luz de novos exemplos de Turismo Geoeducativo a ser explorado.

O olhar turístico dos alunos de da experiência de campo em geografia deve ser um olhar de múltiplas visibilidades. Tal olhar deve reunir atrativos, repulsivos e elementos eventuais menos evidentes da paisagem.

A condução desse olhar é uma construção inacabada, mas sistematizável em etapas de avaliação. O meio estabelece o campo aberto para o estudo. A relação entre os códigos desse meio e a mediação da aula é que poderá traduzir a qualidade do processo.

O professor não deve se iludir com o grau de planejamento do Estudo do Meio. O plano é uma carta de intenção burocrática a ser desmantelada, felizmente, pelas incertezas da vivencia do campo. O inverso disso é um Estudo do Fim ou Um Turismo de passeio no sentido mais pejorativo do termo.

E o aluno não precisa se comportar como turista padrão (todas as instruções do guia docente). A caracterização de um trabalho geoeducativo é, mesmo no ensino fundamental, a ampliação das interações discente com o mundo vivido e / ou estudado.

A distância e ou a relevância do local a ser "investigado" no EM como Turismo Geoeducativo não é fixada de maneira definitiva. Pouco importa também se o roteiro estabelecido fica dentro ou fora do município onde a escola se localiza. O fundamental é a construção desse objeto em campo e as temáticas (conteúdos) que a prática deve suscitar.

\section{Notas}

1 Projeto Visitação: Desafios e Práticas do Turismo Geoeducativo no Estado do Ceará. Coordenado pelo autor e com vigência inicia para três anos de duração.

2 O projeto “Adote seu Rio", apresentado como oficina no I Encontro Estadual de Ensino de Geografia,demarcava uma experiência coletiva de envolvimento direto entre o EM e o movimento social de expressiva ação política nas questões ambientais da Região da Bacia do rio Piracicaba.

3 A Escola e a Agressão ao Meio Ambiente: uma revolução pedagógica. Difel (1974), onde o autor francês, professor da Escola Normal de Paris, analisa a manutenção do processo de alienação ambiental em que se encontrava o ensino em relação as questões ambientais mais emergentes. 


\section{Referências}

CAMARGO, L. O. de L. Sociologia do lazer. In: Turismo, como aprender, como ensinar 2. ANSARAH, M. G. dos R. (Org.). São Paulo: Senac, 2001.

DEBESSE-ARVISET, M. I. A escola e a agressão ao meio ambiente: uma revolução pedagógica. São Paulo. Difel, 1974.

MARCELINO, N. Lazer e educação. Campinas, SP: Papirus, 1990.

MOLINA, S.; RODRIGUEZ, S. Planejamento integral do turismo. São Paulo: Ed. Edusc, 2001.

OLIVEIRA, C. D. M. de. Turismo religioso. São Paulo: Ed. Aleph, 2004.

OLIVEIRA, C. D, M de. Ensino de geografia e ciências da comunicação: por uma geografia mundana. In: Revista Mercator, ano 3, n. 6, 2004.

PONTUSCHKA, N. N. O conceito de estudo do meio transforma-se... em tempos diferentes, em escolas diferentes, com professores diferentes. In: O ensino de geografia no século XXI. VESENTINI, J. W. (Org). p. 249-287. Campinas, SP: Papirus, 2004.

PRUDENTE, H. A. Turismo cultural. As culturas subalternas e o turismo emancipador em Cunha. Taubaté, SP: Cabral Editora e Livraria Universitária, 2005.

REIGOTA, M. Desafios à educação ambiental escolar. In: Educação meio ambiente e cidadania: reflexões e experiências. CASCINO, F.; JACOBI, P; OLIVEIRA, J. F. (Orgs.). São Paulo (Estado) - Sma /Ceam, 1998.

RESENDE, M. S. A Geografia do aluno trabalhador. São Paulo, Atica, 1993.

REZENDE, A. M. de. Concepção fenomenológica da educação. São Paulo: Cortez; Autores Associados, 1990.

YAZIGI, E. A alma do lugar. São Paulo: Contexto, 2001.

CHRISTIAN DENNYS MONTEIRO DE OLIVEIRA - Professor da UFC. Doutor em Geografia pela USP com Pós-doutorado em Comunicação, "Área Turismo" pela Escola de Comunicação e Artes da USP.

Recebido para publicação em junho de 2006

Aceito para publicação em agosto de 2006 